IZA DP No. 8814

The Medical Care Costs of Mood Disorders:

A Coarsened Exact Matching Approach

Stefanie Schurer

Michael Alspach

Jayden MacRae

Greg L. Martin

January 2015 


\title{
The Medical Care Costs of Mood Disorders: A Coarsened Exact Matching Approach
}

\author{
Stefanie Schurer \\ University of Sydney and IZA \\ Michael Alspach \\ Statistics New Zealand \\ Jayden MacRae \\ Compass Health \\ Greg L. Martin \\ Victoria University of Wellington
}

Discussion Paper No. 8814

January 2015

IZA

P.O. Box 7240

53072 Bonn

Germany

Phone: +49-228-3894-0

Fax: +49-228-3894-180

E-mail: iza@iza.org

Any opinions expressed here are those of the author(s) and not those of IZA. Research published in this series may include views on policy, but the institute itself takes no institutional policy positions. The IZA research network is committed to the IZA Guiding Principles of Research Integrity.

The Institute for the Study of Labor (IZA) in Bonn is a local and virtual international research center and a place of communication between science, politics and business. IZA is an independent nonprofit organization supported by Deutsche Post Foundation. The center is associated with the University of Bonn and offers a stimulating research environment through its international network, workshops and conferences, data service, project support, research visits and doctoral program. IZA engages in (i) original and internationally competitive research in all fields of labor economics, (ii) development of policy concepts, and (iii) dissemination of research results and concepts to the interested public.

IZA Discussion Papers often represent preliminary work and are circulated to encourage discussion. Citation of such a paper should account for its provisional character. A revised version may be available directly from the author. 


\section{ABSTRACT}

\section{The Medical Care Costs of Mood Disorders: A Coarsened Exact Matching Approach}

This paper is the first to use the method of coarsened exact matching (CEM) to estimate the impact of mood disorders on medical care costs in order to address the endogeneity of mood disorders. Models are estimated using restricted-use, general practice patient records data from New Zealand for 2009-2012. The CEM model, which exploits a discretization of the data to identify for each patient with a mood disorder a perfect statistical twin, yields estimates of the impact of mood disorders on medical costs that are lower than the estimates obtained from random effects models or conventional matching methods. For example, mood disorders lead to NZ\$366 higher annual medical costs (in 2012 dollars) when perfect balancing of covariates is achieved, while minimal and conventional balancing yield estimated costs of over NZ\$465 and NZ\$400, respectively. The national government expenditures on managing mood disorders is estimated to be $13.4 \%$ of total general practice funding (NZ\$123 Million) based on CEM.

JEL Classification: H51, I18

Keywords: mood disorder, medical care cost, national government expenditures, coarsened exact matching, patient record data, general practice

Corresponding author:

Stefanie Schurer

School of Economics

The University of Sydney

Room 370, Merewether Building

Sydney, NSW 2006

Australia

E-mail: stefanie.schurer@sydney.edu.au

\footnotetext{
* The authors would like to thank for invaluable support and comments from Compass Health staff members, Peter Coombes and Cathy O'Malley, and acknowledge the help provided by Pharmac and the New Zealand Ministry of Health. This study uses clinical, patient-record data provided by Compass Health,Wellington and the conclusions drawn in this study reflect the views of the authors and do not necessarily reflect the views of Compass Health. This study was funded with two Faculty Research Grants $(201276,202326)$ provided by the Victoria Business School, Victoria University of Wellington.
} 


\section{Introduction}

Mood disorders - depression and anxiety - are the fourth-leading cause of life-years lost due to disability worldwide, and the primary cause of loss of health in middle- and high-income countries (Lopez et al., 2006). The 12-month prevalence rates of, for instance, depression in Western European countries suggest that in any year in time up to $10 \%$ of a population suffer from an episode of depression (Greenberg et al., 2003; Thomas and Morris, 2003; Wells et al., 2006). Prevalence rates have grown steadily (Greenberg et al., 2003; Sobocki et al., 2007; Chang et al., 2012; Goldney et al., 2010).

Most patients suffer from their symptoms at repeated intervals (e.g. Roy and Schurer, 2013; Rouillon, 2011). During an acute episode, patients have difficulties to concentrate, are overly tired, lack motivation, and are significantly impaired in mastering daily routines. Such side-effects have been reported to reduce an individual's labor supply (e.g. Stewart et al., 2003) and efficiency while working (e.g. Berndt et al., 1998, 2002). The resulting economic burden of managing mood disorders for society is likely to be large.

As easy-to-use medication became available, many countries, including New Zealand and Australia, have opted to treat mood disorders in a primary care setting to integrate patients better into their communities (Sobocki et al., 2007; Greenberg et al., 2003; Fullerton et al., 2011). New Zealand's Ministry of Health recommended to general practitioners in its Evidence-based Best Practice Guidelines that depression should be treated with both drug regimes and counseling sessions (New Zealand Guidelines Group, 2008). For New Zealand, no study exists that calculates the current national government expenditures on managing mood disorders in general practice.

In this study, we fill this gap by using de-identified, patient-record data from general practice 
consultations of an adult population provided by Compass Health, a Wellington-based primary care service provider, over a period of three years. In contrast to many other studies, which we will review in the next section, we estimate the medical care costs managing these conditions as a proportion of total national expenditures on general practice. We also depart from the general literature by applying coarsened exact matching methods (Ho et al., 2007) to address the potential endogeneity in the experience of mood disorders. Often mood disorders are the direct consequence of the experience of pain-intensive chronic illnesses, which also lead to a high level of health care utilization. Simply summing up all health care costs of individuals diagnosed with mood disorders will therefore overstate their economic burden. Coarsened exact matching methods allow us to carefully separate the medical cost of managing mood disorders from the medical costs caused by co-morbidities.

A crucial advantage of our patient-record data is that we directly observe the clinical diagnoses of mood disorders, and of any other co-morbidity, each service provided to primary-care patients and its price. Knowledge of each service provided allows us to accurately count and calculate each cost component, and therefore to assess the dominant treatment regimes that patients receive. Further, using a sophisticated word-search algorithm, we are able to derive from the GPs' clinical notes for each patient the total days not at work, if a medical certificate was issued, and make statements about the likely cost of lost productivity. Last, the availability of more than half of the total patient population in the area of study enables us to almost exactly match all individuals who suffer from mood disorders with a statistical twin based on a large battery of observable characteristics.

The final purpose of our study is two-fold. On the one hand, we seek to provide a most realistic estimate of the national government expenditures of managing one of the leading causes 
of life-years lost. Such a number is relevant not only to policy-makers as an economic rationale for advocating higher (or lower) levels of expenditures, but also to treasury representatives to understand the leading contributors to government expenditures. On the other hand, we seek to provide an illustration of the usefulness of coarsened exact matching to calculate a realistic figure of public expenditures when endogeneity of the treatment (in our case mood disorders) is of concern.

\section{Economic cost of mood disorders}

To best of our knowledge no study exists on the economic cost, in terms of national government expenditures, of managing mood disorders for New Zealand. Previous studies have assessed this question from a large-scale perspective for various countries in the OECD (Greenberg et al., 2003; Thomas and Morris, 2003; Cuijpers et al., 2007; Sobocki et al., 2007; Chang et al., 2012), across the European Union (Sobocki et al., 2006), and for South Australia (Hawthorne et al., 2003). The existing studies derive their national estimates of the economic burden of mood disorders through an accounting exercise in which the various cost components - the direct cost incurred through health care utilization and the indirect costs that result from lost productivity - are added up. To put the total costs into perspective, these studies compare the relative contribution of direct and indirect to the overall costs, and present the total costs as a proportion of GDP.

A review of this literature (See Table A.1, Online Appendix) shows that the total economic costs amount to about 1\% of GDP in all countries except for South Korea (Chang et al., 2012) and South Australia (Hawthorne et al., 2003) where they represent $0.48 \%$ and $2.1 \%$ of GDP, respectively. In most studies, indirect costs are estimated to be higher than direct medical costs. At the low end are countries from the European Union for which lost productivity makes up 64\% of 
the total costs (Sobocki et al., 2006), whereas at the high end are South Korea and England with a share of 95\% (Chang et al., 2012; Thomas and Morris, 2003). In most other studies, the costs due to lost productivity are 2-3 times larger than the costs due to health care utilization (Sobocki et al., 2006; Greenberg et al., 2003; Cuijpers et al., 2007; Hawthorne et al., 2003).

One reason for the large variation in costs across studies is that the 12-month prevalence rates of depression, which are used as the basis for extrapolating the sample calculations to a nationally representative number, differ widely. For instance, in the US the 12-month prevalence rate is $8.7 \%$, but in South Korea it is only $2.5 \%$. Another reason for the differences in the total cost of depression is the large degree of variation in which cost components are included. Although each of the reviewed studies includes both hospital care and prescription drugs, only five out of the seven studies includes GP consultations.

The studies which have multiple years of data available demonstrate an increase in the economic burden of depression over time, but differ in their conclusions why this may be the case. Greenberg et al. (2003) found that in the US an increase of total costs by $7 \%$ between 1990 and 2000 is mainly driven by an increase in the demand for prescription drugs (452\%) and out-patient services (47\%). In contrast, Sobocki et al. (2007) explained the $100 \%$ increase of the economic burden of depression/anxiety in Sweden that was observed between 1995 and 2007 with an increase of indirect costs by more than $130 \%$.

None of the reviewed studies net out from the total cost the costs attributed to illnesses that coincide or cause depression such as the experience of chronic pain (Eaton, 2002; Frassure-Smith and Lesperence, 1995; Massie, 2004) or other chronic illnesses. In such a scenario, the total costs attributed to mood disorders are likely to be overestimated. 


\section{Data}

In this study we use clinical patient-record data obtained from primary care consultations in New Zealand to calculate the net medical and productivity-related cost of mood disorders. The data are made available by Compass Health which is a non-profit umbrella organization that provides quality management support services to general practitioners and collects data for two major Primary Health Organizations (PHOs) in three districts in the lower North Island: MidCentral, Capital \& Coast and Wairarapa. PHOs are a network of health care providers within New Zealand which were formed in the early 2000s as part of the Government's health reforms. They are funded by District Health Boards (DHB) to support the provision of essential primary health care services through general practices to those people who are enrolled with the PHO. Funding to these providers is based on the number of enrolled patients.

Compass Health manages 101 general practices that represent $88 \%$ of almost half a million patients registered with a primary health-care provider in this area. In exchange for reimbursement, primary health-care providers are contractually obliged to supply Compass Health with utilization data. Such information include the type and total number of services and referrals provided, the prices charged for the service, and patient details.

We acquired special permission to extract the clinical data (diagnosis and clinical notes) from general practices. In total, 50 practices, representing $56.5 \%$ of all patients managed by Compass Health, agreed to participate in this study. Participating practices did not differ in size and location from non-consenting (22) or non-responding (28) practices.

Compass Health provided us with three years of data (mid 2009 to mid 2012). Patients are identified over time by a unique national health number which is assigned for life to patients 
when first time registering with a health-care provider anywhere in New Zealand. Patients were included in the final data set if complete information was available in all three years. Apart from clinical data, the data set contains personal information for each patient, such as date of birth, gender, ethnicity and location of residence. Knowledge of the location of residence allows us to match each individual to the smallest geographic unit available, so-called Meshblocks, for which statistical data is collected by Statistics New Zealand.

Patients were classified as suffering from depression or anxiety if they were diagnosed with depression or anxiety, and/or were prescribed anti-depressant/anti-anxiety medication in any of the three years of data available. We excluded all patients who were diagnosed with any another mental health condition. Diagnosis of depression/anxiety is based on the relevant Read Codes, the most widely used diagnosis classification system in New Zealand general practice (De Lusignan, 2005). As GPs often refrain from assigning a Read Code to a diagnosis, we complement our definition with the prescription of antidepressants, in particular selective serotonin re-uptake inhibitors. ${ }^{1}$ Currently, $10 \%$ of New Zealand's population has been reported to having been prescribed antidepressants since 2006 (Exeter et al., 2009), a number which roughly coincides with the average 12-month prevalence rate (survey based) of depression and anxiety (Wells et al., 2006).

We constructed a measure for the total costs per patient per year by summing the following components:

Cost $_{i t}=\mathrm{GPcon}_{i t} \times \mathrm{P}_{i t}^{\mathrm{GP}}+\mathrm{Pharm}_{i t} \times \mathrm{P}_{i t}^{\mathrm{Ph}}+\mathrm{Path}_{i t} \times \mathrm{P}_{i t}^{\mathrm{Pa}}+\operatorname{Coun}_{i t} \times \mathrm{P}_{i t}^{\mathrm{C}}+A W_{i t} \times W_{\text {age }}$,

\footnotetext{
${ }^{1}$ We included codes for all of the twenty approved antidepressants, but the most common are Paroxetine (Aropax) and Fluoxetine (Prozac). These are also commonly used to treat anxiety (Wells et al., 2006). We consulted two mental health care practitioners to identify an appropriate definition of depression/anxiety in the New Zealand institutional context.
} 
where $C_{i t}$ represents the total costs expressed in New Zealand dollars (referred to as NZ\$) priceadjusted to the second quarter of $2012, i$ and $t$ refer to the individual and year, respectively. The individual cost components are the total number of: (1) General practice consultations GPcon $_{i t}$, (2) prescription drugs Pharm $_{i t}$, (3) pathology tests Path $_{i t}$, (4) counseling services Coun it $_{\text {, and }}$ (5) days absent from work $A W_{i t}$. Each component's total count is multiplied by its current, inflation-adjusted price.

Prices to calculate each cost component are obtained from various sources. Prices for GP consultations $\left(\mathrm{P}_{\mathrm{it}}^{\mathrm{GP}}\right)$ were extracted from patient co-payment data. The prices for prescription drugs $\left(\mathrm{P}_{\mathrm{it}}^{\mathrm{Ph}}\right)$ are obtained from Pharmac, the Government's drug buying agency. We added an extra $\$ 3.00$ to each prescription drug that is charged by the pharmacy dispensing the drug. The price for pathology tests $\left(\mathrm{P}_{i t}^{\mathrm{Ph}}\right)$ was calculated on the basis of a weighted average of prices that we obtained through telephone interviews from four Wellington-based laboratories (Medlab Central Limited, SCL Hawke’s Bay Limited, Hawke’s Bay DHB, Aotea Pathology Limited).

The price of counseling services $\left(P_{i t}^{C}\right)$ was derived from data collected in the Primary Solutions programme run by Compass Health. It is the only subsidized counseling service available to patients with mental health problems. Access to the program is restricted to patients younger than 25 years, from economically weak backgrounds, from Maori or Pacific background, and requires a GP referral. No data are available on privately-financed counseling sessions for which no GP referral is required.

We measure the cost of absenteeism $\left(A W_{i t} \times W a g e_{i}\right)$ as the number of days off work for which a medical certificate is required multiplied by an individual's daily labor-market income. The GP certified days off work are used as a proxy for the actual number of days taken off work in any year. Under New Zealand law employers are able to ask for proof of sickness or injury at any 
time once an employee takes sick leave, but employers are not required to do so. We extracted the time interval for which the days off work were certified with the help of a natural-languageprocessing algorithm to identify the correct number of days. Once we obtained for each patient the total annual number of days off work, we conducted an extensive manual check to ensure the computed days off work matched the actual days off work written in the medical certificate.

As we do not know a patient's actual labor-market income, we use as proxy the median income of the smallest geographic area in which the individual resides (Meshblock). ${ }^{2}$ A daily pay rate is calculated by dividing the Meshblock's median income by the total number of working days in a full year. Our method of estimating income represents a significant improvement over Hawthorne et al. (2003), which use a state average proxy, or Thomas and Morris (2003) and Cuijpers et al. (2007), which use national average income data stratified by age and gender.

\section{Empirical methods}

To estimate the treatment effect of depression and anxiety $\left(D A_{i}\right)$ on the total medical and productivityrelated cost $C_{i t}$, we specify the following model:

$$
C_{i t}=\alpha+\beta D A_{i}+\gamma^{\prime} X_{i t}+\mu_{i}+\eta_{i t}
$$

where $i$ refers to patient $i$ observed in time period $t=2010,2011,2012$. The constant $\alpha$ measures the average costs in the sample. $D A_{i}$ is a dummy variable that takes the value of 1 if the individual belongs to the treatment group (depression/anxiety), and 0 otherwise, and $\beta$ measures the treatment effect of depression/anxiety. The vector $X_{i t}$ captures all control variables for which

\footnotetext{
${ }^{2}$ This proxy is derived from the 2006 National Census conducted and published by Statistics New Zealand, which was at the time of the study the most current Census data available.
} 
the sample characteristics differ between treatment and control group. All remaining variations in costs are captured by individual-specific heterogeneity $\left(\mu_{i}\right)$ and time-period-specific shocks $\left(\eta_{i t}\right)$. This model is estimated with generalized least squares allowing for random effects. Assuming conditional independence and correct functional form, $\beta$ estimates the causal effect of depression/anxiety on total costs.

We complement the regression analysis by employing coarsened exact and conventional matching methods. Matching estimators generally have the advantage that they force the analyst to be transparent about the effective balance of covariates between treatment and control group. Their semi-parametric nature also avoids the potential misspecification of the conditional mean of the outcome of interest, and the arbitrary specification of impact heterogeneity. In small samples matching estimators may lead to a loss of efficiency (See Imbens, 2004).

Coarsened exact matching estimators, in addition, have the advantage that they do not require an ex ante fix of the number of matched units. They control for the number of matches by setting the tuning parameters (Iacus et al., 2011; Ho et al., 2007). The estimator works best in a data scenario in which all or most covariates are discrete, which is the case in our dataset. In a first step, we find a perfect statistical twin for as many members in the treatment group as possible based on the original, categorical data. In a second step, we broaden the category of some control variable (e.g. age) and then find a perfect match for those observations which could not be matched in the first step using the coarsened categories. We repeat this exercise of coarsening the data until we have found a statistical twin for all members in the treatment group. We refer to each step in which we coarsen the data as matching generation. ${ }^{3}$

\footnotetext{
${ }^{3}$ We programmed the search algorithm for the exact statistical twin for each matching generation in Structured Query Language (SQL), which is a special-purpose programming language designed for managing data held in a relational database management system. It is straightforward to use STATA's psmacth2 or R-Project to conduct the CEM procedure.
} 
The following variables are chosen for the exact-matching algorithm: (1) A discrete measure of age, (2) Gender (0,1), (3) Ethnicity (21 categories based on Statistics New Zealand classification), ${ }^{4}$ (4) Economic deprivation of the neighborhood in which the individual lives (five categories), ${ }^{5}$ and (5) nine major chronic health conditions diagnosed on the basis of Read code data (cancer, diabetes, arthritis, respiratory diseases, cardiovascular diseases, degenerative neurological diseases, renal diseases, gastric and intestinal diseases, and lipoid metabolism diseases). Gender, age, and ethnicity are variables that are unaffected by the treatment; economic deprivation of the neighborhood is a fixed characteristic of the area in which the individual resides; little evidence exists in the literature that depression/anxiety causes any of the nine listed chronic diseases, although evidence exists on the effect of chronic illnesses on the onset of depression (Eaton, 2002; Frassure-Smith and Lesperence, 1995; Massie, 2004).

If we cannot find an exact match based on the above criteria (which we will refer to as generation 1), we alter the matching algorithm. ${ }^{6}$ For $66 \%$ of all cases (generation 1), we found a perfect match. When relaxing the continuous measure of age into a five-year interval (generation 2), we exactly matched another $13 \%$ of the sample. When reducing the 21 categories of ethnicity to nine broader categories (see level 1 defined by Statistics New Zealand), we were able to exactly match another $3.4 \%$ of the sample successfully (generation 3 ). For the remaining $17.6 \%$ (generation 4 and 5), we coarsened the data more dramatically (ten-year age intervals, number of co-morbidities in-

\footnotetext{
${ }^{4}$ See for definitions http : //www. stats.govt.nz/methods/classifications-and-standards/ classification-related-stats-standards/ethnicity.aspx

${ }^{5}$ The deprivation score is based on the deprivation index created by Statistics New Zealand, http://www . stats.govt.nz/browse_for_stats/people_and_communities/Geographic-areas/ urban-rural-profile/explanatory-notes.aspx\#moh, which is commonly presented as five quintiles ranging from 1-5, where 5 is the most deprived and 1 the least deprived neighborhood.

${ }^{6}$ For some cases in generation 1 , we found up to nine perfect matches. In this case we chose a random selection procedure to select one single match. For three individuals we could not find any match and these were omitted from this study.
} 
stead of distinct categories, and removing ethnicity from the algorithm). Table A.2 in the Online Appendix shows that the mean values of all observable characteristics are balanced between the treatment and control group even when pooling all five matching generations.

In the case of matching generation 1,2 and 3 the change in the tuning parameter is minimal, which could be tolerated as small measurement error (See Iacus et al., 2011, p. 348). For these three generations, we calculate the average treatment effect on the treated $\left(A \bar{T} T_{t}\right)$ in any particular year $(t)$ as the average difference in total cost between patients diagnosed with, or treated for, depression/anxiety and their statistical twin. Standard errors are calculated using the delta method. The treatment effect is interpreted as the average excess cost of depression/anxiety incurred in the primary care sector and due to lost productivity. When using the sample that includes all five matching generations, we use a regression approach in which we control for the variables that were coarsened into broader categories. ${ }^{7}$

For comparison, we also construct the ATTs using kernel density and nearest-neighbour matching estimators (For an overview Imbens, 2004). The nearest- neighbour estimator is constructed with one match per observation (without replacement), and we choose the match with the shortest distance between treatment-group and control-group unit. In the case of the kerneldensity estimator, we construct a weighted average of the outcomes of all non-treated units where the weight given to each non-treated unit depends on the closeness to the treated unit. Only units with common support are matched, which is the same assumption made in the coarsened exact matching estimator. ${ }^{8}$

\footnotetext{
${ }^{7}$ We alert that there is no statistically significant difference in ATTs when additionally controlling for the covariates in the full sample relative to calculating the raw mean difference. Alternatively, one can use standard matching estimators on the pruned data as employed in Jones et al. (2011). We attempted both regression and matching approaches on the pruned data and obtained almost identical results (available upon request).

${ }^{8}$ We use the the ado program "psmatch2" written by Edwin Leuven and Barbara Sianesi.
} 
Finally, we use the above estimates to calculate the total cost of depression and anxiety to New Zealand's economy (CDA, see Eq. (3)). We obtain the cost ratio between treated and control group (based on the most conservative figure obtained from matching generation 1) and a nationally representative prevalence rate of depression and anxiety:

$$
C D A=\left(\frac{P^{D}\left(R^{C D A}-1\right)}{P^{D} \times R^{C D A}+\left(1-P^{D} \times 1\right)}\right) \times C,
$$

where $\mathrm{P}^{\mathrm{D}}$ is the probability of depression/anxiety in the population, $\mathrm{R}^{\mathrm{CDA}}$ is the ratio of the cost of depression/anxiety over the cost of the statistical twins, and $C$ is the total expenditure on GP services in New Zealand for the reference period. We derive the population prevalence rate of depression and anxiety $\mathrm{P}^{\mathrm{D}}$ by adjusting the prevalence rate obtained from our sample of lower North Island patients with population weights. These population weights are derived from Statistics New Zealand Census data (2006) on age, gender, and ethnicity.

\section{Results}

Our estimation sample consists of 111,575 out of 247,447 eligible patients. We excluded patients who are less than 18 years of age ( $>50 \%$ of sample), who do not have complete data over three years (2\%), and who suffered from alcoholism or a psychotic illness (3\%). In total, the sample includes 26,889 individuals who are diagnosed to suffer from either depression or anxiety or both. The three-year prevalence rate of depression/anxiety in this clinical sample is therefore $24 \%$, which lies within the life-time prevalence rates of depression (16\%) and anxiety (25\%) reported in Wells et al. (2006) (Summary statistics are accessible in Table A.3 in the Online Appendix).

Almost $80 \%$ of the sample are European and $10 \%$ are Maori or Pacific Islanders. Less individ- 
uals are below the age of $30(16.3 \%)$ than there are above 64 years $(20 \%)$, but this is mainly due to our focus on the adult population. More than $17 \%$ carry a Community Services Card, which is means tested and gives the patient access to subsidized GP services and prescriptions. Almost $70 \%$ of the patients live in Capital and Coast, $22 \%$ in Mid-Central, and $8 \%$ in Wairarapa, which is representative of the population. The most common chronic illnesses after mood disorders are respiratory $(12.4 \%)$, lipoid $(9.6 \%)$, and cancer $(8.2 \%)$ disease.

We first discuss the average treatment effect of mood disorders obtained from a random effects model, and compare the average additional costs of depression and anxiety to the average costs of other chronic illnesses. Main estimation results are presented in Table 1. In Model (1) in which we include no further control variables (except for year fixed effects), the average cost of mood disorders per year-per patient is NZ\$465 with standard error (SE) 4.6. When controlling for the basic set of control variables except for health conditions, reduces this average cost by $7 \%$ to NZ\$434 (SE 4.7) (Model (2)). When including measures for the major other health conditions (Model (3)), the average cost of mood disorders is reduced by $14 \%$ to NZ\$372 (SE 4.9). ${ }^{9}$

The included variables in Model (3) explain $18 \%$ of the variation in the medical costs per patient. The average cost of mood disorders are large both in absolute and relative terms. Patients who were identified with depression or anxiety cost per year $\$ 372$ more than patients without mood disorders, ceteris paribus. This is the third highest cost among all other major illnesses considered. Only patients with diabetes (\$549) or cardiovascular disease (\$395) incur higher costs, and these differences are statistically significant at the $5 \%$ level or better.

We now compare the treatment effect of mood disorders with the treatment effects obtained from the various matching methods. Table 2 summarizes the average treatment effect on the

\footnotetext{
${ }^{9}$ Full estimation results of Model (3) are reported in Table A.4 in the Online Appendix.
} 
Table 1: Estimated effects of mood disorders on medical and productivityrelated costs

\begin{tabular}{|c|c|c|c|}
\hline & Model (1) & Model (2) & Model (3) \\
\hline Depression-Anxiety & $\begin{array}{c}465.6^{* * *} \\
(4.6)\end{array}$ & $\begin{array}{c}433.9^{* * * *} \\
(4.7)\end{array}$ & $\begin{array}{c}371.5^{* * *} \\
(4.9)\end{array}$ \\
\hline Year fixed effects & $\checkmark$ & $\checkmark$ & $\checkmark$ \\
\hline Basic controls & & $\checkmark$ & $\checkmark$ \\
\hline Health Conditions & & & $\checkmark$ \\
\hline \multicolumn{4}{|l|}{ Health conditions } \\
\hline Cancer $(0,1)$ & & & $\begin{array}{c}113 . .^{* * *} \\
(7.8)\end{array}$ \\
\hline Diabetes $(0,1)$ & & & $\begin{array}{c}548.7^{* * *} \\
(8.9)\end{array}$ \\
\hline Lipoid metabolism disease $(0,1)$ & & & $\begin{array}{c}124.8^{* * *} \\
(7.4)\end{array}$ \\
\hline Degenerative disease $(0,1)$ & & & $\begin{array}{l}212.8^{* * *} \\
(13.6)\end{array}$ \\
\hline Cardiovascular disease $(0,1)$ & & & $\begin{array}{c}394.7^{* * *} \\
(7.8)\end{array}$ \\
\hline Respiratory disease $(0,1)$ & & & $\begin{array}{c}259.4^{* * *} \\
(6.3)\end{array}$ \\
\hline Arthritis $(0,1)$ & & & $\begin{array}{c}183.8^{* * *} \\
(9.1)\end{array}$ \\
\hline Gastric and intestinal disease $(0,1)$ & & & $\begin{array}{l}224.7^{* * *} \\
(15.9)\end{array}$ \\
\hline Renal disease $(0,1)$ & & & $\begin{array}{l}281.8^{* * *} \\
(14.9)\end{array}$ \\
\hline NT & 334.603 & 334.603 & 334.603 \\
\hline $\mathrm{N}$ & 111.575 & 111.575 & 111.575 \\
\hline R-sq overall & 0.03 & 0.11 & 0.175 \\
\hline
\end{tabular}

${ }^{*} \mathrm{p}<0.1,{ }^{* *} \mathrm{p}<0.05,{ }^{* * *} \mathrm{p}<0.01$. Standard errors in parentheses.

Note: Each model is estimated with generalised least squares (random effects model). Standand errors are reported in parentheses. The dependent variable is 'Total medical and productivity-related costs' denominated in $2012 \mathrm{NZ \$}$. Basic control variables included in Models (2) and (3) are: age groups, sex, ethnicity groups, location, socioeconomic deprivation, median income of area where living, whether the patient is a health care card owner. 
treated (ATT) obtained from coarsened exact matching for the five different matching generations and from standard matching estimators. The most conservative estimate of NZ\$366 (SE 6.26) is obtained from the exact matching algorithm (generation 1). The more generous our matching criteria, the greater is the average treatment effect. Using the full sample of 26,889 matched treatment and control patients, the ATT is NZ\$413 (SE 5.3). The ATTs differ statistically between matching generations 1 and 4/5, but they do not differ statistically between matching generations 1 and 2/3. Both kernel density and nearest neighbor matching estimators yield ATTs of NZ\$403 [SE 4.9] and NZ\$391 (SE 5.7), respectively, and these latter estimates are different in both statistical and economic terms from the most conservative ATT obtained from matching generation 1.

Table 2: Excess costs of depression and anxiety (Average treatment effect of the treated, ATT

\begin{tabular}{lllll}
\hline & $\mathrm{N}$ & ATT (in \$) & SE & $\mathrm{p}^{-\mathrm{val}^{\mathrm{a}}}$ \\
\hline \multicolumn{7}{l}{ Coarsened exact matching } & & & \\
Matching generation 1 & 17747 & 365.6 & 6.26 & \\
Matching generation 1-2 & 21275 & 371.8 & 5.83 & 0.210 \\
Matching generation 1-3 & 22201 & 371.7 & 5.70 & 0.200 \\
Matching generation 1-4 & 26723 & 411.7 & 5.34 & 0.000 \\
Matching generation 1-5 & 26889 & 413.1 & 5.34 & 0.001 \\
Standard matching estimators & & & \\
Kernel density matching 26813 & 403.1 & 4.86 & 0.001 \\
Nearest neighbor matching6812 & 391.9 & 5.64 & 0.001 \\
\hline
\end{tabular}

Note: Standard errors are calculated with the delta method. ${ }^{\mathrm{a}} \mathrm{p}$-value refers to z-statistic on the hypothesis that ATT in this row is statistically the same as ATT of matching generation 1.

We continue our subsequent analysis of the excess counts and costs by expenditure component on the basis of matching generation 1, because it yields the most conservative estimates. However, the results from all five generations, in conjunction with the standard matching estimates can be used to put bounds around the likely cost estimate. The upper panel of Table 3 re- 
ports the excess annual count of services by expenditure group. Patients with depression/anxiety, on average, visit a GP four more times per year, obtain five more prescriptions and 2.3 more referrals for pathology tests. They have 0.5 more episodes of days off work that require a medical certificate and spend less than a tenth of a day not working than comparable patients without depression/anxiety. All differences are statistically significant at the $1 \%$ level.

The lower panel of Table 3 reports the differences in excess cost of depression/anxiety by expenditure category. By far, the largest component in the total excess burden are prescription drugs (NZ\$192), but patients with depression/anxiety also incur NZ\$70 more in consultation fees, and NZ\$16 more in pathology tests. Lost productivity costs are low, with a difference of NZ\$65 per year. Also, the excess cost of counseling sessions is minimal at $\mathrm{NZ} \$ 15$. The latter is not surprising because only a very small group of disadvantaged individuals gets access to these subsidized counseling sessions, and the total number is limited to six sessions per year.

Also reported in Table 3 are the cost and count ratios (column 3) and their standard errors (column 4) that indicate by how much larger were the expenditures of patients with depression/anxiety per year relative to the control group. The cost for consultations are 1.5 times greater for depression/anxiety patients than for their statistical twins, whereas prescription cost and lost productivity cost are 1.8 times higher. In total, the annual costs of patients with depression/anxiety are 1.7 times greater than for patients who are identical to the depression/anxiety group in all other relevant characteristics. All ratios are statistically significant different from 1.

Based on the above estimates, we calculated the net direct cost of managing depression and anxiety as a share of national general practice expenditures and as percentage of national GDP. The cost ratio (excluding lost productivity) is 1.71 whereas the population-weighted prevalence rate of depression is 0.217 . For the relevant time period (2012), Crown expenditures on general 
Table 3: Excess count and costs of depression and anxiety and ratios, by expenditure

\begin{tabular}{lrrrr}
\hline & ATT & SE $^{\mathrm{a}}$ & Ratio & SE \\
\hline Excess counts & & & & \\
Consultation & 4.36 & 0.047 & 1.514 & 0.007 \\
Prescriptions & 5.23 & 0.057 & 1.789 & 0.012 \\
Pathology Tests & 2.28 & 0.053 & 1.412 & 0.009 \\
Subsidized counseling sessions & 0.12 & 0.005 & 21.012 & 2.593 \\
Times off Work & 0.44 & 0.032 & 1.855 & 0.082 \\
Days off Work & 0.09 & 0.004 & 1.712 & 0.012 \\
Excess costs & & & & \\
Consultations & 77.0 & 1.067 & 1.51 & 0.007 \\
Prescriptions & 192.4 & 2.760 & 1.79 & 0.012 \\
Pathology Tests & 16.5 & 0.403 & 1.41 & 0.009 \\
Subsidized counseling sessions & 14.8 & 0.540 & 21.01 & 2.593 \\
Lost productivity & 65.0 & 4.999 & 1.85 & 0.082 \\
Total cost & 365.6 & 6.261 & 1.71 & 0.012 \\
\hline
\end{tabular}

Note: a Standard errors of Average Treatment Effect on the Treated (ATT) are calculated with delta method. ${ }^{b}$ The standard errors of the cost and count ratios are bootstrapped with 1000 replications.

practice funding were $\$ 855$ million (New Zealand Treasury, 2012), while the Accident Compensation Corporation (ACC) spent a total of \$64.5 million on General Practice services (GPs, Nurses and Nurse Practitioners under Cost of treatment regulations and Rural GP and PRIME contracts), both expressed in $2012 \mathrm{NZ} \$$. In total, the combined national expenditures on GP services were $\$ 920$ million. $^{10}$

Using equation (3), the net direct costs of managing depression and anxiety are \$123 million [95\% CI \$114.7-\$131.4]. This indicates that the government spent on all patients suffering from depression/anxiety between $\$ 115$ and $\$ 131$ million, which makes up between $12.5-14.2 \%$ of all GP expenditures. Given nominal GDP in New Zealand in 2012 of $\$ 200$ billion, New Zealand's GPs provided treatments and services to manage depression/anxiety of at least $0.057-0.066 \%$ of GDP.

\footnotetext{
${ }^{10}$ All figures are adjusted for inflation to be able to express the expenditures in 2012 NZ\$.
} 


\section{Conclusion}

This is the first study to estimate the direct and indirect cost of managing mood disorders, depression and anxiety, in the New Zealand primary health care system. Using coarsened exact matching estimators, we estimate a conservative lower-bound estimate of the net cost of managing depression and anxiety in general practice as $13.4 \%$ of total primary care expenditures, or NZ\$366 per patient per year when including lost productivity. More than $82 \%$ of these additional costs are incurred by direct, i.e. medical expenditure, while the remaining $18 \%$ are incurred by lost productivity. Almost two-thirds of the medical expenditures are driven by prescription drugs, $26 \%$ by consultation fees, and $5 \%$ by pathology tests. Less than $5 \%$ of the total medical costs are incurred through subsidized counseling services, which appears to stand at odds with the large contribution of prescription drugs. Total costs for patients with depression or anxiety are 1.7 times greater than the costs observed for patients that are not suffering from the condition. In combination with our calculation of a three-year prevalence rate of depression/anxiety of 21 percent, this excess cost ratio implies a GP-managed economic burden of mood disorders of at least $0.06 \%$ of GDP.

Two important conclusions can be drawn from our analysis: (1) similar to trends in the US (Pratt et al., 2011), Australia (Stephenson et al., 2013), and the UK (Spence, 2013), New Zealand's general practitioners tend to manage depression and anxiety mainly with antidepressant medication, and may even oversubscribe them (Exeter et al., 2009). Publicly subsidized counseling sessions are only available to a small group of individuals from disadvantaged backgrounds despite the Ministry of Health's guidelines to use both drug regimes and counseling sessions (New Zealand Guidelines Group, 2008); (2) the high cost of lost productivity due to depression/anxiety 
documented in previous studies for other countries may be entirely driven by informal days taken off work, which makes it difficult to accurately measure and monitor the indirect burden of mood disorders.

Our estimates are smaller than estimates of the economic burden of mood disorders in the international literature because we net out the costs incurred through illnesses, age, and socioeconomic disadvantage that correlate strongly with mental health problems. One could argue however that the nature of our data makes it likely to underreport the prevalence of depression and anxiety, which will then lead to a smaller nationally-representative cost calculation. For instance, Cuijpers et al. (2004) found that those suffering minor depression were eight times less likely to utilize a health-care service than their severely depressed counterparts, while less than $50 \%$ of individuals with depression seek care (Wittchen et al., 2001; Kessler et al., 2003; Groom et al., 2003). Nevertheless, our three-year prevalence rate is in line with the 12-month prevalence rates reported in New Zealand's Mental Health Survey (Wells et al., 2006) and in the Dunedin Cohort Study (16.7\%) for the same age group (Moffitt et al., 2010).

An important limitation of our study is the omission of costs incurred by in-patient service utilization. There is good reason to suggest that this omission will not invalidate our cost calculations. Similar to Australia, in New Zealand mood disorders are predominantly managed by primary care organizations due to a health-care-reform process that started in the mid-1990s. The National Mental Health Strategy was launched in 1994 by the New Zealand Government with the aim to (1) 'decrease the prevalence of mental illness and mental health problems within the community', and (2) 'to increase the health status of and reduce the impact of mental disorders on consumers, their families, care-givers and the general community' (Ministry of Health, 1994). Subsequent publications and the establishment of the Mental Health Commission in 1996 helped 
to raise awareness about the high prevalence of mental health problems in the population and the need to include family and the community in its management (Mental Health Commission, 2012). The Ministry of Health's Evidence-based Best Practice Guideline for the treatment of depression explicitly recommended to refer only the most severe cases of mental health problems, those in imminent danger, to secondary care (New Zealand Guidelines Group, 2008).

In contrast to New Zealand, the economic burden of mood disorders in Australia is widely cited to be a staggering $\mathrm{A} \$ 12.6$ billion with six million work days lost per year (e.g. Manicavasagar, 2012). These estimates are referred back to numbers published on the Beyond Blue webpage, a non-governmental organization that seeks to raise awareness about mood disorders. However, to the best of our knowledge we were unable to identify a report that describes the method that resulted in such a large cost calculation. It would be worthwhile replicating our analysis to derive a lower bound of the costs of managing mood disorders in Australia. Lower-bound estimates of these costs are useful for the Australian Treasury and Ministry of Health to monitor and forecast the expenditure burden of a major chronic illness.

\section{References}

Berndt, E.R., Bir, A., Busch, S.H., Frank, R.G. and Normand, S.L.T. (2002), 'The medical treatment of depression, 1991 - 1996: productive inefficiency, expected outcome variations, and price indexes', Journal of Health Economics, 21(3), 373-396.

Berndt, E.R., Finkelstein, S.N., Greenberg, P.E., Howland, R.H., Keith, A., Rush, A., Russell, J. and Keller, M.B. (1998), 'Workplace performance effects from chronic depression and its treatment', Journal of Health Economics, 17(5), 511-535. 
Chang, S., Hong, J.P. and Cho, M. (2012), 'Economic burden of depression in South Korea', Social Psychiatry and Psychiatric Epidemiology, 1-7.

Cuijpers, P., de Graaf, R. and van Dorsselaer, S. (2004), 'Minor depression: risk profiles, functional disability, health care use and risk of developing major depression', fournal of Affective Disorders, 79(1-3), 71-79.

Cuijpers, P., Smit, F., Oostenbrink, J., De Graaf, R., Ten Have, M. and Beekman, A. (2007), 'Economic costs of minor depression: a population-based study', Acta Psychiatrica Scandinavica, 115(3), 229-236.

De Lusignan, S. (2005), 'Codes, classifications, terminologies and nomenclatures: definition, development and application in practice', Informatics in Primary Care, 13, 65-69.

Eaton, W. (2002), 'Epidemiological evidence on the comorbidity of depression and diabetes', fournal of Psychosomatic Research, 53, 903-906.

Exeter, D., Robinson, E. and Wheeler, A. (2009), 'Antidepressant dispensing trends in new zealand between 2004 and 2007', Australian \& New Zealand Journal of Psychiatry, 43, 1131-1140.

Frassure-Smith, N. and Lesperence, F. (1995), 'Depression and 18-month prognosis after myocardial infarction', Circulation, 19, 999-105.

Fullerton, C.A., Busch, A.B., Normand, S.L.T., McGuire, T.G. and Epstein, A.M. (2011), ‘Ten-year trends in quality of care and spending for depression.', Archives of General Psychiatry, 68(12), $1218-1226$.

Goldney, R.D., Eckert, K.A., Hawthorne, G. and Taylor, A.W. (2010), 'Changes in the prevalence 
of major depression in an Australian community sample between 1998 and 2008', Australian and New Zealand Journal of Psychiatry, 44(10), 901-910.

Greenberg, P.E., Kessler, R.C., Birnbaum, H.G., Leong, S.A., Lowe, S.W., Berglund, P.A. and CoreyLisle, P.K. (2003), 'The economic burden of depression in the United States: How did it change between 1990 and 2000?', fournal of Clinical Psychiatry, 64(12), 1465-1475.

Groom, G., Hickie, I. and Davenport, T. (2003), Out Of Hospital, Out Of Mind! Report Detailing Mental Health Services in Australia in 2002 and Community Priorities for National Mental Health Policy for 2003-2008, Mental Health Council of Australia, Canberra.

Hawthorne, G., Cheok, F., Goldney, R. and Fisher, L. (2003), 'The excess cost of depression in South Australia: a population-based study', Australian and New Zealand fournal of Psychiatry, 37(3), 362-373.

Ho, D., Kosuke, I., Kin, G. and Stuart, E. (2007), 'Matching as nonparametric preprocessing for reducing model dependence in parametric causal inference', Political Analysis, 15, 199 Ü236.

Iacus, S.M., King, G. and Porro, G. (2011), 'Multivariate matching methods that are monotonic imbalance bounding', fournal of the American Statistical Association, 106(493), 345-361.

Imbens, G. (2004), 'Semi-parametric estimation of average treatment effects under exogeneity: A review', The Review of Economics and Statistics, 86, 4-29.

Jones, A.M., Rice, N. and Rosa Dias, P. (2011), 'Long-term effects of school quality on health and lifestyle: Evidence from comprehensive schooling reforms in England', fournal of Human Capital, 5(3), 342-376. 
Kessler, R.C., Berglund, P., Demler, O., Jin, R., Koretz, D., Merikangas, K.R., Rush, A.J., Walters, E.E. and Wang, P.S. (2003), 'The epidemiology of major depressive disorder: Results from the national comorbidity survey replication (ncs-r)', fournal of the American Medical Association, 289(23), 3095-3105.

Lopez, A., Mathers, C., Ezzati, M., Jamison, C. and Murray, D. (2006), 'Measuring the global burden of disease risk factors: 1990 - 2001', A. Lopez, C. Mathers, M. Ezzati, C. Jamison and D. Murray (eds.), Global Burden of Disease and Risk Factors, The World Bank and Oxford University Press, Oxford.

Manicavasagar, V. (2012), 'A review of depression diagnosis and management', InPsych, February.

Massie, M. (2004), 'Prevalence of depression in patients with cancer', Fournal of the National Cancer Institute Monographs, 32, 56-71.

Mental Health Commission (2012), Blueprint II: Improving mental health and wellbeing for all New Zealanders, How things need to be, Technical report, Mental Health Commission.

Ministry of Health (1994), Looking forward: strategic directions for the mental health services, Technical report, Ministry of Health.

Moffitt, T.E., Caspi, A., Taylor, A., Kokaua, J., Milne, B.J., Polanczyk, G. and Poulton, R. (2010), 'How common are common mental disorders? evidence that lifetime prevalence rates are doubled by prospective versus retrospective ascertainment', Psychological Medicine, 40(6), 899-909.

New Zealand Guidelines Group (2008), Identification of common mental disorders and management of depression in primary care: Summary, Technical report. 
New Zealand Treasury (2012), Health Projections and Policy Options for the 2013 Long-term Fiscal Statement, Financial statement, New Zealand Treasury.

Pratt, L., Brody, D. and Gu, Q. (2011), Antidepressant Use in Persons Aged 12 and Over: United States, 2005-2008, Data Brief 76, NCHS.

Rouillon, F. (2011), 'What do depressive episodes tell us about depressive disorder', Medicographia, 33(2), 113-118.

Roy, J. and Schurer, S. (2013), 'Getting stuck in the blues: The persistence of depression in Australia', Health Economics, 22(9), 1139-1157.

Sobocki, P., Jönsson, B., Angst, J. and Rehnberg, C. (2006), 'Cost of depression in Europe', Journal of Mental Health Policy and Economics, 9(2), 87-98.

Sobocki, P., Lekander, I., Borgström, F., Ström, O. and Runeson, B. (2007), 'The economic burden of depression in Sweden from 1997 to 2005', European Psychiatry, 22(3), 146 - 152.

Spence, D. (2013), 'Are antidepressants overprescribed? Yes', British Medical fournal, 346, f191.

Stephenson, C.P., Karanges, E. and McGregor, I.S. (2013), 'Trends in the utilisation of psychotropic medications in australia from 2000 to 2011', Australian and New Zealand fournal of Psychiatry, 47(1), 74-87.

Stewart, W., Ricci, J., Chee, E., Hahn, S. and Morganstein, D. (2003), 'Cost of lost productive work time among us workers with depression', fournal of the American Medical Association, 289(23), $3135-3144$. 
Thomas, C.M. and Morris, S. (2003), 'Cost of depression among adults in England in 2000', The British Journal of Psychiatry, 183, 514-519.

Wells, J.E., Oakley Browne, M.A., Scott, K.M., McGee, M.A., Baxter, J., Kokaua, J. and for the New Zealand Mental Health Survey Research Team (2006), 'Te Rau Hinengaro: The New Zealand Mental Health Survey: overview of methods and findings', Australian and New Zealand Journal of Psychiatry, 40(10), 835-844.

Wittchen, H., Holsboer, F. and Jacobi, F. (2001), Met and unmet needs in the management of depressive disorder in the community and primary care: The size and breadth of the problem, Technical report, Max Planck Society. 
ONLINE APPENDIX - NOT FOR PUBLICATION 


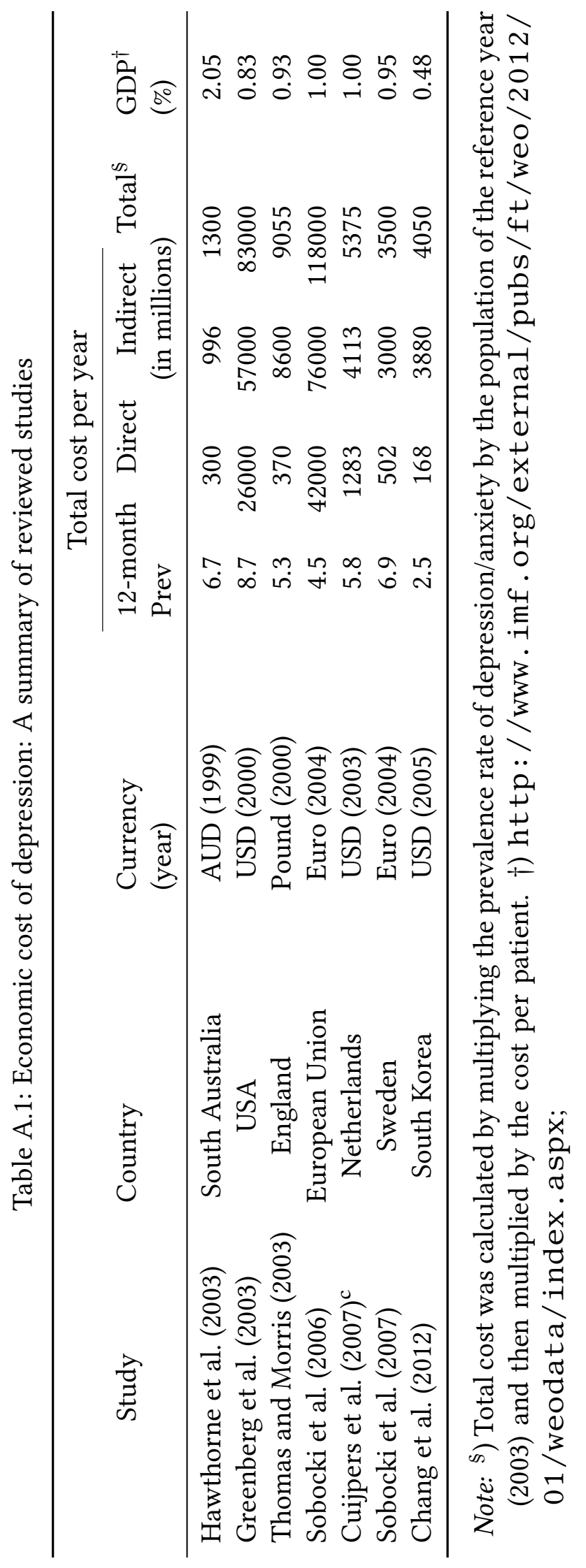




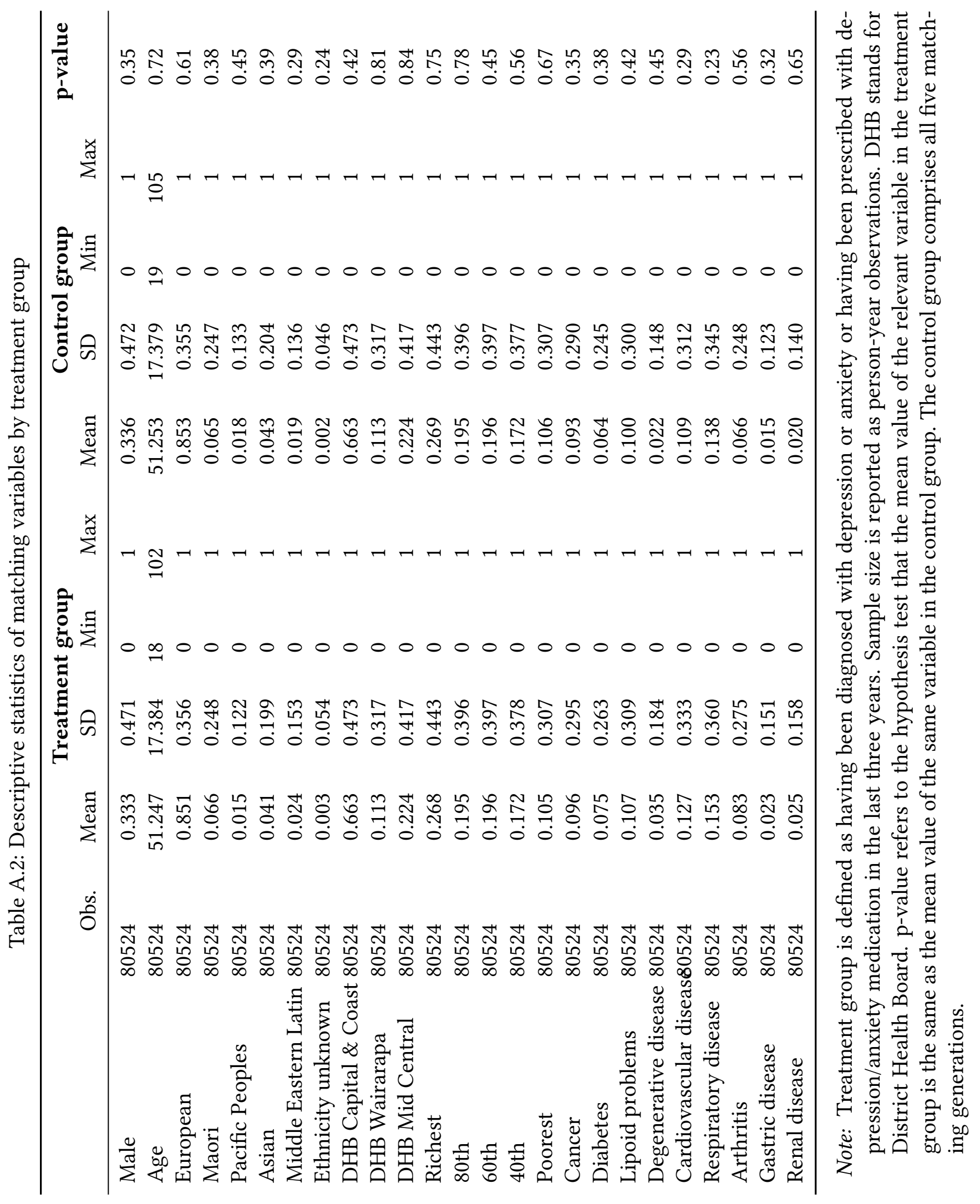


Table A.3: Descriptive statistics for eligible sample

\begin{tabular}{|c|c|c|c|c|c|}
\hline & Obs. & Mean & SD & Min & $\operatorname{Max}$ \\
\hline Depressed and anxiety & 334603 & 0.240 & 0.427 & 0 & 1 \\
\hline Male & 334603 & 0.441 & 0.496 & 0 & 1 \\
\hline European Ethnicity & 334603 & 0.798 & 0.402 & 0 & 1 \\
\hline Maori Ethnicity & 334603 & 0.074 & 0.261 & 0 & 1 \\
\hline Pacific Peoples Ethnicity & 334603 & 0.027 & 0.162 & 0 & 1 \\
\hline Asian Ethnicity & 334603 & 0.073 & 0.260 & 0 & 1 \\
\hline Middle Eastern Latin Ethnicity & 334603 & 0.025 & 0.155 & 0 & 1 \\
\hline Age $18-19$ & 334603 & 0.015 & 0.123 & 0 & 1 \\
\hline Age 20-24 & 334603 & 0.081 & 0.273 & 0 & 1 \\
\hline Age $25-29$ & 334603 & 0.067 & 0.250 & 0 & 1 \\
\hline Age $30-34$ & 334603 & 0.069 & 0.254 & 0 & 1 \\
\hline Age $35-39$ & 334603 & 0.087 & 0.281 & 0 & 1 \\
\hline Age $40-44$ & 334603 & 0.101 & 0.301 & 0 & 1 \\
\hline Age $45-49$ & 334603 & 0.107 & 0.309 & 0 & 1 \\
\hline Age $50-54$ & 334603 & 0.102 & 0.302 & 0 & 1 \\
\hline Age 55-59 & 334603 & 0.087 & 0.282 & 0 & 1 \\
\hline Age $60-64$ & 334603 & 0.079 & 0.270 & 0 & 1 \\
\hline Age $65-69$ & 334603 & 0.064 & 0.245 & 0 & 1 \\
\hline Age $70-74$ & 334603 & 0.052 & 0.222 & 0 & 1 \\
\hline Age $75-79$ & 334603 & 0.037 & 0.189 & 0 & 1 \\
\hline Age $80-85$ & 334603 & 0.028 & 0.166 & 0 & 1 \\
\hline Age $85-89$ & 334603 & 0.017 & 0.129 & 0 & 1 \\
\hline Age $90+$ & 334603 & 0.008 & 0.089 & 0 & 1 \\
\hline High-user health care card & 334603 & 0.006 & 0.076 & 0 & 1 \\
\hline Community Services Card & 334603 & 0.173 & 0.378 & 0 & 1 \\
\hline Region: Capital and Coast & 334603 & 0.695 & 0.460 & 0 & 1 \\
\hline Region: Wairarapa & 334603 & 0.083 & 0.277 & 0 & 1 \\
\hline Region: Mid-Central & 334603 & 0.222 & 0.415 & 0 & 1 \\
\hline Cancer & 334603 & 0.082 & 0.275 & 0 & 1 \\
\hline Diabetes & 334603 & 0.063 & 0.242 & 0 & 1 \\
\hline Lipoid problems & 334603 & 0.096 & 0.294 & 0 & 1 \\
\hline Degenerative disease & 334603 & 0.024 & 0.153 & 0 & 1 \\
\hline Cardiovascular disease & 334603 & 0.097 & 0.296 & 0 & 1 \\
\hline Respiratory disease & 334603 & 0.124 & 0.330 & 0 & 1 \\
\hline Arthritis & 334603 & 0.059 & 0.235 & 0 & 1 \\
\hline Gastric and intestinal disease & 334603 & 0.017 & 0.130 & 0 & 1 \\
\hline Renal disease & 334603 & 0.021 & 0.142 & 0 & 1 \\
\hline Year 2010 & 334603 & 0.333 & 0.471 & 0 & 1 \\
\hline Year 2011 & 334603 & 0.333 & 0.471 & 0 & 1 \\
\hline Year 2012 & 334603 & 0.333 & 0.471 & 0 & 1 \\
\hline Median income in stat area & 334603 & 150.103 & 45.720 & 11.68 & 371 \\
\hline Average cost & 334603 & 630.953 & 1017.988 & 0 & 88345 \\
\hline Transaction count & 334603 & 9.087 & 9.457 & 0 & 428 \\
\hline Days off work per episode & 334603 & 0.555 & 4.708 & 0 & 362 \\
\hline Number of episodes off work per year & 334603 & 0.127 & 0.523 & 0 & 21 \\
\hline Number of subsidized counseling sessions & 334603 & 0.033 & 0.517 & 0 & 27 \\
\hline Number of scripts & 334603 & 9.440 & 13.541 & 0 & 266 \\
\hline Transaction costs & 334603 & 166.833 & 192.323 & 0 & 10578 \\
\hline Off-work cost & 334603 & 78.480 & 697.190 & 0 & 86585 \\
\hline Laboratory cost & 334603 & 6.909 & 11.021 & 0 & 615 \\
\hline Counseling cost & 334603 & 4.024 & 61.576 & 0 & 2711 \\
\hline Laboratory costs & 334603 & 52.173 & 80.668 & 0 & 3496 \\
\hline Total script costs & 334603 & 329.444 & 555.595 & 0 & 25886 \\
\hline
\end{tabular}


Table A.4: Full estimation results of Model (3): Determinants of total medical and productivity-related costs

\begin{tabular}{|c|c|c|c|c|}
\hline & Coef & SE & t-stat & p-value \\
\hline Depression-Anxiety & 371.523 & 4.943 & 75.160 & 0.000 \\
\hline Male $(0,1)$ & -112.273 & 4.237 & -26.500 & 0.000 \\
\hline Maori (Base: European) & 19.242 & 8.119 & 2.370 & 0.018 \\
\hline Pacific Peoples & 34.651 & 12.951 & 2.680 & 0.007 \\
\hline Asian & -65.855 & 8.121 & -8.110 & 0.000 \\
\hline Middle Eastern Latin & -52.992 & 13.337 & -3.970 & 0.000 \\
\hline Ethnicity unknown & -71.215 & 32.838 & -2.170 & 0.030 \\
\hline Deprivation: 80 th percentile (Base: Richest) & 1.822 & 5.978 & 0.300 & 0.761 \\
\hline 60 th & -5.685 & 6.078 & -0.940 & 0.350 \\
\hline 40th & -13.419 & 6.675 & -2.010 & 0.044 \\
\hline Poorest & -23.249 & 8.165 & -2.850 & 0.004 \\
\hline Deprivation Quintile unknown & -24.085 & 9.273 & -2.600 & 0.009 \\
\hline Age 15-19 (Base 45-49) & -57.967 & 17.879 & -3.240 & 0.001 \\
\hline Age $20-24$ & -41.675 & 9.680 & -4.310 & 0.000 \\
\hline Age 25-29 & -46.859 & 10.206 & -4.590 & 0.000 \\
\hline Age $30-34$ & -35.095 & 10.090 & -3.480 & 0.001 \\
\hline Age 35-39 & -28.269 & 9.447 & -2.990 & 0.003 \\
\hline Age $40-44$ & -26.749 & 9.056 & -2.950 & 0.003 \\
\hline Age 50-54 & 48.280 & 9.048 & 5.340 & 0.000 \\
\hline Age 55-59 & 105.323 & 9.468 & 11.120 & 0.000 \\
\hline Age $60-64$ & 165.921 & 9.783 & 16.960 & 0.000 \\
\hline Age 65-69 & 230.801 & 10.506 & 21.970 & 0.000 \\
\hline Age $70-74$ & 264.446 & 11.441 & 23.110 & 0.000 \\
\hline Age $75-79$ & 305.027 & 13.101 & 23.280 & 0.000 \\
\hline Age $80-85$ & 407.172 & 14.630 & 27.830 & 0.000 \\
\hline Age $85-89$ & 432.816 & 17.926 & 24.140 & 0.000 \\
\hline Age $90+$ & 429.510 & 24.604 & 17.460 & 0.000 \\
\hline High-user service card $(0,1)$ & 1009.332 & 27.377 & 36.870 & 0.000 \\
\hline Community services card $(0,1)$ & 107.830 & 6.108 & 17.650 & 0.000 \\
\hline DHB Wairarapa (Base: Capital Coast) & -28.490 & 7.750 & -3.680 & 0.000 \\
\hline DHB Mid-Central & 37.298 & 5.294 & 7.040 & 0.000 \\
\hline Cancer $(0,1)$ & 113.880 & 7.753 & 14.690 & 0.000 \\
\hline Diabetes & 548.729 & 8.893 & 61.700 & 0.000 \\
\hline Lipoid metabolism disease & 124.841 & 7.400 & 16.870 & 0.000 \\
\hline Degenerative disease & 212.755 & 13.581 & 15.670 & 0.000 \\
\hline Cardiovascular disease & 394.677 & 7.768 & 50.810 & 0.000 \\
\hline Respiratory disease & 259.360 & 6.297 & 41.190 & 0.000 \\
\hline Arthritis & 183.788 & 9.120 & 20.150 & 0.000 \\
\hline Gastric and intestinal disease & 224.649 & 15.859 & 14.170 & 0.000 \\
\hline Renal disease & 281.759 & 14.888 & 18.930 & 0.000 \\
\hline Year 2011 (Base year 2010) & -14.021 & 3.210 & -4.370 & 0.000 \\
\hline Year 2012 & 23.745 & 3.210 & 7.400 & 0.000 \\
\hline Constant & 341.979 & 7.748 & 44.140 & 0.000 \\
\hline NT & 334603 & & & \\
\hline $\mathrm{N}$ & 111575 & & & \\
\hline R-sq: within & 0.001 & & & \\
\hline R-sq between & 0.277 & & & \\
\hline R-sq overall & 0.175 & & & \\
\hline
\end{tabular}

Note: The model is estimated with generalised least squares (random effects model). The dependent variable is 'Total medical and productivity-related costs' denominated in 2012 NZ\$. 